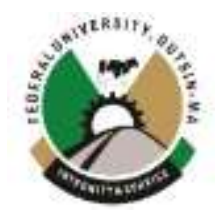

\title{
ENTOMOLOGICAL SURVEY OF MOSQUITO VECTORS OF LYMPHATIC FILARIASIS IN TALATAN-MAFARA AND TSAFE LOCAL GOVERNMENT AREAS OF ZAMFARA STATE, NIGERIA
}

\author{
*Aliyu, A. A., Sow, G. J. and Ndams, I. S. \\ Department of Zoology, Ahmadu Bello University, Zaria \\ *Corresponding Author's Email: binmalikone@yahoo.com
}

\begin{abstract}
Entomological survey of mosquito vectors was carried out to determine species abundance and identify those responsible for the transmission of lymphatic filariasis in Talatan-mafara and Tsafe Local Government Areas of Zamfara State, Nigeria. Houses were randomly selected for mosquito collection. Aerosol (Baygon) was sprayed in the rooms to knockdown indoor resting mosquitoes. A total of 5,230 mosquitoes comprising of 3,104 females and 2,126 males were collected and 1,182 engorged females were dissected to isolate filarial worm, Wuchereria bancrofti. The species of mosquitoes encountered include Culex quinquefasciatus (84\%), Anopheles funestus (10\%) and Anopheles gambiae sl. (6\%). The overall infection and infectivity rates of the mosquitoes with Wuchereria bancrofti were $1.86 \%$ and $1.44 \%$ respectively. The infection/infectivity rates of Culex quinquefasciatus, Anopheles funestus and Anopheles gambiae sl. were 1.01\%/0.51\%, 2.97\%/2.97\% and $4.54 \% / 4.14 \%$ respectively.
\end{abstract}

Keywords: Anopheles funestus, Anopheles gambiae, sl., Culex quinquefasciatus, Lymphatic filariasis, Talatanmafara, Tsafe

\section{INTRODUCTION}

Filariasis is caused by parasitic nematode commonly called "filariae". The thread-like (filarial) adult parasites live in the vessels, tissues or body cavities of the vertebrate hosts. The female worms are viviparous and produce microscopic embryos called 'microfilariae' (Anosike et al., 2005). The microfilaria (mf) circulates in the blood or migrate through the skin from where they are ingested by vectors during blood meal. In Nigeria, the microfilariae of Wuchereria bancrofti exhibit nocturnal periodicity appearing between the hours of $10 \mathrm{pm}$ and 4:00am before they leave peripheral circulation almost completely during the day time (Anosike et al., 2005). Matured adult stages reside either in the lymphatic system or in connective tissues (Ottesen, 1984). When picked up by the vector, the microfilariae increase in size, moult and finally develop into infective filariform larvae (L3) (Nwoke et al., 2010).

Wuchereria bancrofti is the most common cause of lymphatic filariasis (LF), accounting globally for approximately $90 \%$ of all infections (Lenhart et al., 2006). The disease is transmitted by species of mosquitoes of the genera Aedes, Anopheles, Culex and Mansonia (Nissen et al., 2002). In order to eliminate filariasis, some level of success has been achieved through mass drug administration; reducing the global prevalence from over 120 million (WHO, 1997) to 67.88 people (Ramaiha and Ottesen, 2014).

The World Health Organisation targeted lymphatic filariasis for elimination mainly through a strategy of mass drug administration (MDA) (Abel et al., 2002) which depends on the consumption of the recommended drug (Mariappan, 2007).
However, non-compliance has led to low treatment coverage (Gyapong and Twum-Danso, 2006). Although, MDA alone has been shown to suppress transmission of lymphatic filariasis in many areas where it has been implemented, it is often accompanied by resurgence once there is residual infection in the population (Abel et al., 2002). Therefore, sustained suppression of lymphatic filariasis could be achieved only through integration of different strategies of vector control along with MDA (Mariappan, 2007). This investigation is an attempt to determine the abundance of different species of mosquitoes as well as identify those responsible for the transmission of lymphatic filariasis in two Local Government Areas of Zamfara State, Nigeria.

\section{MATERIALS AND METHODS}

\section{Study Area}

Zamfara State is located in the North-western region of Nigeria. Tsafe and Talatan-mafara lie between $12^{\circ} 10^{\prime}-13^{\circ} 10^{\prime} \mathrm{N}$ and $6^{\circ}$ $15^{\prime}-7^{\circ} 15^{\prime}$ E. Talatan-Mafara is about one hundred (100) kilometers west while Tsafe is about fifty (50) kilometers east from Gusau the State Capital.

The ethnic groups include: Hausa (dominant), Fulani and few of bare-bari (Kanuri). The major economic activities of the people are farming and rearing of animals, although some are engaged in trading. The people especially in the rural areas are living in thatched houses virtually unprotected from mosquito bites especially during the hot dry season. 


\section{Climate and Vegetation}

The vegetation is Sudan savannah characterized by short and scattered trees (ZSG, 2011). Annual rainfall ranges from 36 $80 \mathrm{~mm}$ in the months of June to October. The hottest months (March to May) have approximately $40^{\circ} \mathrm{C}-45^{\circ} \mathrm{C}$ and the coolest months (December to February) have range of $20^{\circ} \mathrm{C}-25^{\circ} \mathrm{C}$ (ZSG, 2011).

\section{Collection and Dissection of Mosquitoes}

Three wards from each local government area were randomly selected, in each ward, two to four sites were randomly sampled Two to five houses were sampled from each site and one to three rooms in each house were sprayed using pyrethrin-based insecticide between the hours of 6:00am and 8:30am following the method of Dosson et al. (1995) and Veronica et al. (2014). Fifteen to twenty-five (15 - 25) minutes later knocked down mosquitoes were collected from each room into separate containers, well labelled and taken to laboratory for further studies.

\section{Identification of mosquitoes' species}

Dissecting microscope and hand lens were used for detail observation and identification of the mosquitoes with particular reference to the head, thorax, wing and abdomen as described by standard taxonomic keys by Highto (1983) and WHO (1975). Morphological characteristics such as length of maxillary palp, wing spot, mouthpart and abdominal end were observed. The identified species were recorded and kept for further studies.

\section{Dissection of mosquitoes}

Engorged females were individually picked and placed on a slide and appendages (wings, legs antennae and palps) gently removed. Dissection was carried out as described by WHO (1975). The content of the dissected parts was carefully observed under a light microscope (using $\times 40$ objective) for the presence of larval stages; first, second and third instar larvae (L1, L2 and L3). The infected mosquito and number of microfilariae present were noted and recorded. Infection and infectivity rates were calculated respectively using the formulae below:
Infection Rate $=$

Number of infected mosquitoes (L1, L2 and L3) Larvae)

Number of mosquitoes examined

Number of infected mosquitoes with L3 Larvae Larvae)

Infectivity Rate $=$ $\times 100$

$\times 100$

Number of mosquitoes examined

\section{RESULTS}

\section{Mosquito Abundance}

A total of 5,252 mosquitoes which comprises 3,104 females' and 2,148 males' mosquitoes were collected indoors from 123 houses in Tsafe and Talatan-mafara local government areas between the months of March and September, 2015. In Tsafe Local Government Area, a total of 520 and 1,830 mosquitoes were collected in dry and wet seasons respectively while in Talatan-mafara 689 and 3,010 mosquitoes were collected in dry and wet seasons respectively (Table 1). Mosquito abundance varied significantly between dry and wet seasons across the locations in Tsafe LG but did not vary significantly in Talatan-Mafara (Table 2). The comparison of mosquito abundance with respect to locations in Talatan-Mafara however, showed that there were significant variations between location one (Galadima) and two others locations (Ruwan-Bore and Kayayi) but there was no significant variation between Ruwan-Bore and Kayayi (Table 4). 
Table 1: Mosquito abundance in Tsafe local government area during the dry and wet seasons

\begin{tabular}{|c|c|c|c|c|}
\hline Locations (Wards) & Study Sites & $\begin{array}{l}\text { No. of Mosquito } \\
\text { (Dry season) }\end{array}$ & $\begin{array}{l}\text { No. of Mosquito } \\
\text { (Wet season) }\end{array}$ & Total \\
\hline \multirow[t]{4}{*}{ Tsafe Central } & Bakin tumbi & I50 (30.0 \pm 3.4$)$ & $400(80.0 \pm 11.4)$ & 550 \\
\hline & Tashar hanne & $180(36.0 \pm 4.1)$ & $370(93.0 \pm 15.2)$ & \\
\hline & Shiyar magazu & $50(13.0 \pm 1.0)$ & $270(68.0 \pm 4.1)$ & \\
\hline & Magajin gari & $30(10.0 \pm 0.9)$ & $140(47.0 \pm 3.1)$ & 550 \\
\hline \multirow[t]{5}{*}{ Magazu } & Tudun-Muntsira & $45(9.0 \pm 0.4)$ & $230(77.0 \pm 2.4)$ & \\
\hline & Sabon-gari & $20(7.0 \pm 0.7)$ & $100(33.0 \pm 2.5)$ & \\
\hline & Kucheri central & $15(4.0 \pm 0.5)$ & $120(30.0 \pm 3.16)$ & 320 \\
\hline & Ruwa kusa & $30(8.0 \pm 0.7)$ & $200(40.0 \pm 3.73)$ & \\
\hline & P. Value & 0.83789 & 0.88478 & 170 \\
\hline
\end{tabular}

Kucheri

Table 2: Mosquito abundance in respect to locations in Tsafe Local Government Area during the dry and wet seasons

\begin{tabular}{lccc}
\hline \multicolumn{1}{c}{ Locations (Wards) } & Dry season & Wet season & Total \\
\hline Tsafe Central & $330(33.00 \pm 19.05)^{\mathrm{a}}$ & $770(86.0 \pm 49.39)^{\mathrm{a}}$ & 1100 \\
& $125(10.00 \pm 6.01)^{\mathrm{b}}$ & $640(64.0 \pm 36.95)^{\mathrm{b}}$ & 765 \\
Magazu & $65(6.00 \pm 3.41)^{\mathrm{c}}$ & $420(36.0 \pm 20.73)^{\mathrm{c}}$ & 485
\end{tabular}

Kucheri

Means along the same column with different superscript are significantly different at $(\mathrm{P}<0.05)$.

Numbers in parenthesis are means \pm Standard error 
Table 3: Mosquito abundance in Talatan-mafara local government area during the dry and wet seasons

\begin{tabular}{llcrc}
\hline $\begin{array}{l}\text { Locations } \\
\text { (Wards) }\end{array}$ & Study Sites & Dry season & Wet season & Total \\
\hline Galadima & Kwanan-Damma & $200(40.0 \pm 3.3)$ & $428(86.0 \pm 12.3)$ & 628 \\
& Anguwan-Rogo & $270(54.0 \pm 5.6)$ & $1437(359.0 \pm 59.6)$ & 1707 \\
& Tsakuwa & $60(15.0 \pm 0.8)$ & $852(21.0 \pm 1.5)$ & 912 \\
Ruwan-Bore & Ruwan-Bore & $60(6.0 \pm 0.5)$ & $60(15.0 \pm 2.2)$ & 155 \\
& Milkidi & $42(8.0 \pm 1.2)$ & $68(23.0 \pm 3.2)$ & $10(18.0 \pm 2.4)$ \\
Kakin-Zaje & $27(7.0 \pm 0.6)$ & 0.99230 & 102 \\
& Kayatawa & $30(10.0 \pm 0.5)$ & & 95 \\
& P. value & 0.97973 & & 100
\end{tabular}

Mosquito density was low in the dry season compare to the months of August to October (raining season) however it does not differ significantly between dry and wet season as $\mathrm{P}$. value $=0.32(\mathrm{P}>0.05)$. Numbers in parenthesis are means \pm Standard error

Table 4: Mosquito abundance in respect to locations in Talatan-Mafara Local Government Area during the dry and wet seasons

\begin{tabular}{lccc}
\hline \multicolumn{1}{c}{ Locations (Wards) } & Dry season & Wet season & Total \\
\hline Galadima & $530(38.00 \pm 21.86)^{\mathrm{a}}$ & $2717(150.0 \pm 86.6)^{\mathrm{a}}$ & 3247 \\
& $102(7.00 \pm 4.16)^{\mathrm{b}}$ & $155(19.0 \pm 11.0)^{\mathrm{b}}$ & 257 \\
& $57(8.00 \pm 4.70)^{\mathrm{b}}$ & $138(20.0 \pm 11.4)^{\mathrm{b}}$ & 195
\end{tabular}

Ruwan-Bore

\section{Kayayi}

Comparison of mosquitoes' density with respect to locations in Talatan-Mafara LG showed that Means along the same column with different superscript are significantly different at $(\mathrm{P}<0.05)$.

Numbers in parenthesis are means \pm Standard error

\section{Mosquito Species Composition}

The species of mosquitoes collected during the period of study include; Cx. quinquefasciatus 4,373 (83\%), An. funestus 515 (10\%) and An. gambiae sl. 324 (7\%). Out of the three species of mosquitoes recorded in the dry season in Tsafe LGA, Cx. quinquefasciatus 431 (85\%) was found to be dominant while An. funestus 52 (10\%) did not differ significantly from An. gambiae sl. 26 (5\%). Similarly, in wet season, $C x$. quinquefasciatus 1474 (80\%) dominated but there was no significant variation between An. funestus 199 (11\%) and An. gambiae sl. 157(9\%) (Table 5).

In Talatan-Mafara LGA, Cx. quinquefasciatus 487 (74\%) was found to be the dominant species followed by An. funestus 96 (15\%) then An. gambiae sl. 74 (11\%) in dry season. Statistically, there were no significant variation between Cx. quinquefasciatus, An. funestus and An. gambiae sl. (P>0.05). Likewise, in wet season, Cx. quinquefasciatus 1981 (89\%) was found to be dominant followed by An. funestus 168 (7\%) then An. gambiae sl. 85 (4\%). There was no significant variation in abundance between $C x$. quinquefasciatus, An. funestus and An. gambiae sl. (P>0.05) in Talatan-Mafara LG during wet season (Table 6). 
Table 5: Mosquito species composition in Tsafe local government area during the months of March to May (dry season) and July to September $(n=3)$

\begin{tabular}{lccc}
\hline Species & Dry season & Wet season & Total \\
\hline Cx. quinquefasciatus & $431(54.0 \pm 37.2)^{\mathrm{a}}$ & $1474(184.0 \pm 68.7)^{\mathrm{a}}$ & 1905 \\
An. ${ }^{\mathrm{a}}$ funestus & $52(7.0 \pm 2.7)^{\mathrm{b}}$ & $199(25.0 \pm 10.5)^{\mathrm{b}}$ & 251 \\
& $26(3.0 \pm 1.7)^{\mathrm{b}}$ & $157(20.0 \pm 9.0)^{\mathrm{b}}$ & 183 \\
An. gambiae s.l. & 0.032723 & 0.000267 & \\
P. Value & & &
\end{tabular}

Means along the same column with different superscript are significantly different $(\mathrm{P}<0.05)$.

Numbers in parenthesis are means \pm Standard error

Table 6: Mosquito species composition in Talatan-mafara local government area during the dry and wet seasons

\begin{tabular}{lccc} 
Species & Dry season & Wet season & Total \\
\hline Cx. quinquefasciatus & $487(70.0 \pm 37.2)^{\mathrm{a}}$ & $1981(283.0 \pm 485.3)^{\mathrm{a}}$ & 2468 \\
& $96(14.0 \pm 5.1)^{\mathrm{a}}$ & $168(24.0 \pm 10.90)^{\mathrm{a}}$ & 264 \\
An. funestus & $74(11.00 \pm 4.49)^{\mathrm{a}}$ & $85(12.00 \pm 7.75)^{\mathrm{a}}$ & 159 \\
An. gambiae sl. & 0.205387 & 0.195562 &
\end{tabular}

P. Value

Means along the same column with the same superscript are not significantly different $(\mathrm{P}>0.05)$

\section{Infection Rates of Mosquitoes}

Of the 3,104 female mosquitoes collected from the study area, 1182 engorged (blood fed) females were dissected (Table 7 and 8). The species of mosquitoes dissected include: Culex quinquefasciatus 792 (67\%), Anopheles funestus 236 (20\%) and Anopheles gambiae sl. 154 (13\%).

The infection rate of mosquitoes in dry and wet seasons in Tsafe Local Government were $1.76 \%$ and $2.50 \%$ respectively while Talatan-Mafara Local Government had $0.85 \%$ and $3.44 \%$ in dry and wet seasons respectively. The infection rate of mosquitoes in both seasons were significantly different in Tsafe (Table 7) and Talatan-Mafara (Table 8) Local government Area $(\mathrm{P}<0.05)$. Out of three species of mosquitoes examined during the dry season in Tsafe Local Government, Wuchereria bancrofti was recorded in $2(5.6 \%)$ An. funestus out of 35 dissected and 2 (1.1\%) Cx. quinquefasciatus out of 179 dissected but none was recorded in An. gambiae sl. However, during the wet season, Wuchereria bancrofti was recorded in all of the three species of mosquitoes examined, during the wet season, highest prevalence of Wuchereria bancrofti was found recorded in 3 (9.1) out of 33 dissected An. gambiae sl. followed by $A n$. funestus 3 (6.4\%) infected out of 47 dissected and the least was recorded in Cx. quinquefasciatus species 4 (1.3) infected out of 320 dissected (Table 7). On the other hand, during the dry season in Talatan-Mafara Local Government, Wuchereria bancrofti was recorded in An. gambiae sl. 1 (1.8\%) infected out of 55 dissected, An. funestus 1 (1.4\%) infected out of 73 dissected and none was recorded in $C x$. quinquefasciatus. Whereas during the wet season, 6 (7.5\%) An. funestus were recorded infected out of 80 dissected, An. gambiae sl. 3 (5.6\%) out of 54 dissected and Cx. quinquefasciatus 2 (1.1) out of 186 dissected (Table 8). 
Table 7: Prevalence of Wuchereria bancrofti in mosquitoes in Tsafe Local Government Area during the dry and wet seasons $(\mathbf{n}=3)$

\begin{tabular}{llccc} 
Seasons & Species & No. examined & No. infected & Prevalence (\%) \\
\hline Dry & Cx. Quinquefasciatus & $179(22.0 \pm 10.8)$ & 2 & 1.1 \\
& An. funestus & $36(5.0 \pm 2.1)$ & 2 & 5.6 \\
\multirow{2}{*}{ Wet } & An. gambiae sl. & $12(2.0 \pm 0.8)$ & & \\
& Cx. quinquefasciatus & $320(40.0 \pm 7.1)$ & 3 & 0.0
\end{tabular}

9.1 There was significant difference $(\mathrm{P}<0.05)$ in mosquitoes' infection rate between dry and wet season in Tsafe LG.

Table 8: Prevalence of Wuchereria bancrofti in mosquitoes in Talatan-mafara Local Government Area during the dry and wet seasons

\begin{tabular}{llccc}
\hline Seasons & Species & No. examined & No. infected & Prevalence (\%) \\
\hline Dry & Cx. quinquefasciatus & $107(15.0 \pm 22.0)$ & 0 & 0.0 \\
& An. funestus & $73(10.0 \pm 7.0)$ & 1 & 1.4 \\
& An. gambiae sl. & $55(8.0 \pm 6.4)$ & 1 & 1.8 \\
Wet & Cx. quinquefasciatus & $186(3.0 \pm 11.5)$ & 2 & 1.1 \\
& An. funestus & $80(11.0 \pm 5.1)$ & 3 & 7.5 \\
& An. gambiae sl. & $54(8.0 \pm 4.0)$ & & 5.6
\end{tabular}

\footnotetext{
Mosquitoes' infection rate between dry and raining season in Talatan-Mafara showed no statistically significant difference at $(\mathrm{P}<0.05)$.
} 
In comparison, the infection rate of mosquitoes with Wuchereria bancrofti between Tsafe and Talatan-Mafara LG, the three species of mosquitoes examined in Tsafe LG. Highest prevalence of Wuchereria bancrofti was recorded in An. gambiae sl. 3(6.7\%) followed by An. funestus 5(6.0\%), the least was recorded in Cx. quinquefasciatus 6(1.2\%), while in Talatan-Mafara LG, highest prevalence was recorded in An. funestus 6 (3.9\%) followed by An. gambiae sl. 4 (3.7\%), least was in Cx. quinquefasciatus 2(0.7\%). However, there was no statistically significant difference in infection rate between the two local governments at $(\mathrm{P}>0.05)($ Table 9).

Table 9: Comparison in infection rate of mosquitoes by Wuchereria bancrofti in Tsafe and Talatan-Mafara Local Government Area

\begin{tabular}{llccc}
\hline LGAs & Species & No. examined & No. infected & Prevalence (\%) \\
\hline Tsafe & Cx. quinquefasciatus & 499 & 6 & 1.20 \\
& An. funestus & 83 & 5 & 6.02 \\
& An. gambiae sl. & 45 & 3 & 6.67 \\
Talatan- & Cx. quinquefasciatus & & 2 & 0.68 \\
Mafara & An. funestus & 293 & 6 & 3.92 \\
& An. gambiae sl. & 153 & 4 & 3.67 \\
\end{tabular}

The comparison in infection rate between two LGAs showed statistically, there was no significant variation $(\mathrm{P}>0.05)$.

\section{Infectivity Rate of Mosquitoes}

The infectivity rate of mosquitoes in Tsafe during dry and wet seasons were $0.88 \%$ and $1.50 \%$ respectively while Talatan-Mafara had $0.85 \%$ and $2.19 \%$ in dry and wet seasons respectively. The overall infectivity rate of mosquitoes with Wuchereria bancrofti was higher in Talatan-Mafara LG 10 (2.5\%) than Tsafe LG 4 (1.8\%). Some mosquitoes harbored more than one filarial worm, but not more than four In Tsafe Local Government, infectivity rates with Wuchereria bancrofti were An. gambiae sl. 2 (4.4\%), An. funestus 3 (3.6\%) and Cx. quinquefqsciatus $3(0.6 \%)$ whereas in Talatan-Mafara Local Government, infectivity rates were An. gambiae sl. 4 (3.8\%), An. funetus $4(2.6 \%)$ and Cx. quinquefqsciatus $1(0.3 \%)$ (Table 10).

Table 10: Infectivity rate of mosquitoes by Wuchereria bancrofti in Tsafe and Talatan-Mafara Local Government Area

\begin{tabular}{llccc}
\hline LGAs & Species & No. examined & $\begin{array}{c}\text { No. infected with L3 } \\
\text { larvae }\end{array}$ & Prevalence (\%) \\
\hline Tsafe & Cx. quinquefasciatus & 499 & 3 & 0.60 \\
& An. funestus & 83 & 3 & 3.61 \\
& An. gambiae sl. & 45 & 2 & 4.44 \\
Talatan- & Cx. quinquefasciatus & & & 0.34 \\
Mafara & An. funestus & 293 & 1 & 2.61 \\
& An. gambiae sl. & 153 & 4 & 3.67
\end{tabular}

The infectivity rate between two LGAs did not vary significantly $(\mathrm{P}>0.05)$.

\section{DISCUSSION}

\section{Mosquito abundance}

Mosquito population was found to be high in the main towns (headquarters) of both local governments during the wet season. This could be due to the fact that the sites (headquarter) consist of high human population compare to other sites (locations) within the L.G.A(s), weather prevalent at the time of collection and nature of the drainage systems. Large number of mosquitoes observed during the wet season is in contrast with the finding of Okorie et al. (2014) that mosquitoes were more abundant during the dry months of December, January and February compared to the wet months of March, April, May, June and July in Ibadan. Generally, places with high human population (urban areas) seem to harbour more mosquitoes than the places with 
low human population (rural areas); mosquitoes' egg can only get ripe (matured) with the availability of blood meal therefore, it could be as a result of what make those mosquitoes to search for where their host is available. For instance, Galadima ward (urban) had the highest abundance of mosquitoes which are generally Culex quinquefasciatus Moreover, the practice of husbandry is taking place in the area (cows, sheep and goats are reared at the backyard of many houses) which also attract mosquito for blood meal. Tsafe Central ward (headquarter of the LG) also had high population density of mosquito, a poor drainage systems was observed leading to stagnant water thus creating a favourable breeding site for $C x$. quinquefasciatus.

The low population of Anopheles funestus (0.7\%) and An. gambiae sl. $(0.3 \%)$ in Galadima (urban) were probably due to unfavourable breeding habitat for the species as the water bodies were contaminated and the contaminated water bodies do not favour breeding activities for both A. funestus and A. gambiae. Hence, the predominant mosquitoes in the location were Culex quinquefasciatus. This agrees with the findings of (Nwoke et al., 2014) that the increase of Culex species population is in line with the growth of towns, poor sanitation as well as industrialization.

Generally, Culex quinquefasciatus was dominant in urban and semi urban in the study area while Anopheles gambiae sl. and Anopheles funestus were dominant in rural the dominant of Anopheles species in the rural could be as due to the fact rural water bodies usually tend to be less polluted and those species of mosquito preferred unpolluted water for breeding activities hence found more in rural areas in order to favour its breeding. This is also in line with the findings that $C x$. quinquefasciatus has increased in many towns due to increasing urbanization and resultant proliferation of unsanitary collections of water (Service, 1989) and Amechi et al. (2011). As a result of the urban overcrowding, the sanitation services in most of the urban areas, especially at the urban-periphery or squatter settlements are unable to cope adequately with the influx of people (WHO, 2010).

\section{Infection/infectivity rate of mosquitoes}

High infection/infectivity rates were recorded in Anopheles gambiae sl. and Anopheles funestus had in the rural areas and Culex quinquefasciatus in the urban and semi-urban areas. This is in line with the findings of Brengus (1975) that in Nigeria and other African countries, Anopheles gambiae, which breeds mainly in temporary habitats such as pools, puddles, hoof point, burrow pits etc. and Anopheles funestus, which breeds in numerous shallow, shaded, grassy streams and rivers are the natural vectors of Wuchereria bancrofti in the rural areas. There are also similar reports that Anopheles gambiae and Anopheles funestus are the main vectors in rural Nigeria while Culex quinquefasciatus remains the main vectors in urban and semiurban areas (Oduola and Awe, 2006; Nwoke et al., 2010).

Similar observations were made where Anopheles gambiae, Anopheles funestus and Culex quinquefasciatus have been incriminated as vectors of Wuchereria bancrofti in an irrigation community in southern Ghana (Dzodzomenyo et al., 1999; Onapa et al., 2001). Anopheles funestus and Anopheles gambiae were found to be the vectors of Wuchereria bancrofti in three communities in Uganda (Anosike et al., 2005). Culex quinquefasciatus and some Anopheles sp (Anopheles gambiae and Anopheles funestus) incriminated as vectors of filarial nematodes in Ebonyi State, Nigeria.

The infection/infectivity rate in Tsafe local government area was higher in wet season. This agrees with the findings of Badaki (2010) that transmission of bancroftian infection occurs mainly during rainy season when mosquitoes are most abundant.

Galadima and Tsafe Central wards (the headquarters of TalatanMafara and Tsafe local government areas respectively), recorded low infection rate. This could be as a result of the ongoing mass drug administration in the state. The project has been able to cover almost all the communities in the main towns and may have contributed to the reduction of Wuchereria bancrofti in both vectors and human. In some rural areas like Kucheri and Ruwan-bore wards, the project of mass drug administration is yet to reach them. Fortunately, the programme is ongoing and hopefully every point of the state (rural and urban) will be covered. The low infection/infectivity rate recorded in Kayayi ward, though a rural setting could be attributed to the few number of mosquitoes collected and dissected during the study period.

The overall microfilaria infection rate $(8.55 \%)$ and infectivity rate $(5.42 \%)$ in mosquitoes from the present study is comparable to reports from filariasis endemic countries (WHO, 1999; Pedersen and Mukolo, 2012). However, it is much higher than what was reported by Dogara et al. (2012) from Kano State Nigeria, where he recorded overall infection/infectivity rates of $0.07 \%$ and $0.0 \%$ respectively. This differences could be as a result of location (the work had been carried out in Kano State while this current study had been carried out in Zamfara State) and also could be as a result of the use of insecticide in Kano State has high impact to reduce the mosquito population.

\section{CONCLUSIONS}

There are three mosquito species in the study area namely; Culex quinquefasciatus, Anopheles funestus and Anopheles gambiae. Culex quinquefasciatus is the dominant species. All species of mosquitoes were infected with the filarial worm Wuchereria bancrofti

\section{ACKNOWLEDGEMENTS}

The authors are grateful to the Zamfara State Ministries of Health and Local Government for permission to carry out the work. We also appreciate the support of all the staff of Tsafe and Talatan-mafara local government(s) health unit, village/ward leaders and the entire people of the two local governments where the study was carried out. 


\section{REFERENCES}

Ahorlu, C. K., Dunyo, S. K.. and Asamoah, G. (2001). Consequences of hydrocoele and the benefits of hydrocelectomy: a qualitative study in lymphatic filariasis endemic communities on the coast of Ghana. Acta Tropica, 80: 215- 221.

Amechi, A.A., Nwoke, B. E. B. and Ukaga, C. N. (2011). A Comparative study of Human Lymphatic Filariasis, Vectors and Filarial transmission Indices Control Trial Using insecticide Treated Bednet (ITBN) in Ebonyi state, Nigeria. Global research Journal of science, 7(1): 2276-8300.

Anosike, J.C.; Nwoke, B.E.; Ajayi, E.G.; Onwuliri, C.O., Okoro, O.U., Oku, E.E., Asor, J.E., Amajuoyi, O.U., Ikpeama, C.A., Ogbusu, F.I. and Meribe, C.O. (2005). Lymphatic filariasis among the Ezza People of Ebonyi State, Eastern Nigeria, Annals of Agriculture and Environmental Medicine, 12:181-186.

Badaki J.A. and Akogun O.B. (2010). Severe morbidity due to lymphatic filariasis in Taraba State, Nigeria. Nigerian Journal of Parasitology, 41: 161-163.

Das, P.K. and Ramaiah, K.D. (2002). Entomological monitoring of annual mass drug administration for the control or elimination of lymphatic filariasis. Annals of Tropical Medicine and Parasitology, 2, $39-142$.

Dogara, M.M., Nock, H.I., Agbede, R.I.S., Ndams, I.S. and Joseph, K.K. (2008). Entomological survey of mosquitoes responsible for transmission of lymphatic filariasis in three endemic villages in Kano State, Nigeria. Advances in Disease Surveillance, 5: 25.

Dzodzomenyo, M. and Simonsen, P.E. (1999). Bancroftian filariasis in an irrigation project community in southern Ghana. Tropical Medicine and International Health, 4: 13-18

Gyapong, J. and Amuyunzu-Nyamongo, M. (1999). Issues Relating to the Integration of Elimination of Lymphatic Filariasis with Onchocerciasis Control Programmes in Africa. Unpublished.

Lenhart, A., Eigege, A., Kal, A., Pam, D., Miri, E.S., Gerlong, G., Oneyka, J., Sambo, Y., Danboyi, J., Ibrahim, B., Dahl, E., Kumbak, D., Dakul, A., Jinadu, M.Y., Umaru, J., Richards, F.O. and Lehmann T. (2006). Contributions of different mosquito species to the transmission of lymphatic filariasis in central Nigeria: Implications for monitoring infection by PCR in mosquito pools. Filarial Journal, 6(14): 1475-2883.
Mariappan, T. (2007). Vector control in lymphatic filariasis elimination programme. Current Science, 93(8): 1061.

Nissen, D.M.W., Walker, C.J., Johann-Liang R, Pharm, D.K., Tolan, R.W. and Steel, R. (2002). Bancroftian filariasis;

Retrieved from

http://www.emedicine.com/ped/topic205.htm on18/11/2002.

Nwoke, B.E.B., Nwoke, E.A., Ukaga, C.N. and Nwachukwu, M.I. (2010). Epidemiological characteristics of Bancroftian filariasis and the Nigerian environment. Public health parasitology and entomology unit, Evan Enwerem University, Owere, Imo State, Nigeria. Pp 76-78

Oduola, A.O. and Awe, O.O. (2006). Behavioural Biting preference of Culex quinquefasciatus in human host in Lagos metropolis, Nigeria. Journal of Vector Borne Diseases, (43): 1620.

Okorie, K. P. K., Patricia N. O., Olayemi M. A., Kolade T. I. and George O. A. (2014). Species composition and temporal distribution of mosquito populations in Ibadan, Southwest Nigeria. Journal of Entomology and Zoology studies, 7: 98 100.

Ottesen, E. A. (1984). Filariasis and tropical eosinophilia In: Tropical and Geographical Medicine. Warrenks and Mahmoud, A. A. F. (eds). McGraw-Hill Inc. New York. 390 - 422

Pedersen, E.M and Mukolo, D.A. (2012). Impact of insecticidetreated materials on filarial transmission by the various species of vector mosquito in Africa. Annals of Tropical Medicine and Parasitology, 8: 120-131.

Ramaiha, K. D. and Ottesen, E. A. (2014). Progress and impact of 13 years of the Global Programme to Eliminate Lymphatic Filariasis on reducing the burden of filarial disease. Plos Neglected Tropical Diseases, 8(11): 3319.

Sasa, M. (1997). Human filariasis: a global survey of epidemiology and control. University Tokyo press, Japan. 451460.

Service, M. W. (2012). Medical Entomology for Students. $5^{\text {th }}$ Edition Cambridge University Press, New York, 303.

World Health Organization (1975). Manual on practical entomology in malaria. Part I and II. Methods and techniques. World Health Organization Offset Publication, Geneva, Switzerland; 13(1): 160 .

World Health Organization. (1999). Expert committee on vector biology and control. Geneva $6^{\text {th }}-10^{\text {th }}$ December, World Health Organisation, 8(2): 110-112. 
World Health Organization. (2010). Global programme to eliminate lymphatic filariasis: Progress report on mass drug administration. Weekly Epidemiology Record, 86:377-388.

World Health Organization. (1997). Lymphatic Filariasis: Reasons for Hope. Edited by Dzenowagis J. Geneva, World Health Organization.

Zamfara State Government (ZSG). (2011). Inside Zamfara. Zamfara State Press Unit. Pp 17-25.

(C)2020 This is an Open Access article distributed under the terms of the Creative Commons Attribution 4.0 International license viewed via https://creativecommons.org/licenses/by/4.0/ which permits unrestricted use, distribution, and reproduction in any medium, provided the original work is cited appropriately. 